\title{
Scars in depression: is a conceptual shift necessary to solve the puzzle?
}

\author{
M. Wichers ${ }^{1 *}$, N. Geschwind ${ }^{1}$, J. van Os $^{1,2}$ and F. Peeters ${ }^{1}$ \\ ${ }^{1}$ Department of Psychiatry and Psychology, South Limburg Mental Health Research and Teaching Network, EURON, Maastricht University, \\ Maastricht, The Netherlands \\ ${ }^{2}$ Division of Psychological Medicine, Institute of Psychiatry, London SE5 8AF, UK
}

\begin{abstract}
Although clinical findings suggest that in the aftermath of depression a process of 'scarring' may ensue, research examining the issue of 'scars' (including biological, psychological and cognitive changes) has remained largely inconclusive. This paper proposes a new approach to the concept of 'scars' that is (i) based on a dimensional view of depression, (ii) uses methods that take into account the dynamic interplay between the person and his context, (iii) differentiates between scars following depression and scars following the factor that actually caused the depression such as stress and (iv) introduces a dynamic view of the concept of 'scars' in that it hypothesizes that scars can wax and wane. This approach may stimulate the discovery of new entries in the puzzle underlying the ontogenesis of vulnerability and resilience. Furthermore, it may provide insights that help to develop new therapies for depression.
\end{abstract}

Received 11 November 2008; Revised 8 May 2009; Accepted 20 May 2009; First published online 23 July 2009

Key words: Depressive disorder, dimensional approach, experimental designs, treatment.

\section{Introduction}

Major depressive disorder (MDD) is, at least in secondary and more specialized care settings with morbidity concentration, a chronic psychiatric disorder with residual symptoms, frequent relapses and estimates of recurrence ranging from $33 \%$ to $70 \%$ within several years (Pettit et al. 2006).

Previous research has shown that the causal role of severe life events is smaller in recurrences than in firstonset episodes of MDD (Monroe \& Harkness, 2005; Stroud et al. 2008). This observation was described by Post (1992) as a process of behavioural 'sensitization' and electrophysiological 'kindling', suggesting that a depressive episode leaves some traces that persist after remission and recovery, and render individuals vulnerable to the onset of new episodes under the influence of only moderate or, eventually, no psychosocial stress. This idea is known as the scar hypothesis of depression (Lewinsohn et al. 1981). Scar theories assume that something, presumably encoded at the biological level, changes during an episode of depression, inducing a long-lasting change and increasing the likelihood of future episodes (Burcusa \& Iacono, 2007). Scar research, however, is not confined to the

* Address for correspondence: Dr M. Wichers, Department of Psychiatry and Psychology, South Limburg Mental Health Research and Teaching Network, EURON, Maastricht University,

Vijverdalseweg 1, Concorde building, Maastricht, The Netherlands.

(Email: m.wichers@sp.unimaas.nl) neurobiological domain. Studies examining scars in depression have focused on potential scars within a broad variety of domains (psychosocial, cognitive, emotional and others) (Shea et al. 1996; Ormel et al. 2004a; Beevers et al. 2007; Burcusa \& Iacono, 2007). In this paper, therefore, the term 'scar' may refer to all possible changes in cognition, emotion, behaviour or biology that develop in the aftermath of a depressive mood state and result in a stable increase in vulnerability.

Studies that address the scar hypothesis ideally assess putative factors that may become scarred before and after an episode of MDD in participants without residual symptoms. In studies that attempted to apply such a rigorous design, several potential scars were examined including depression-related cognitions (Lewinsohn et al. 1981; Barnett \& Gotlib, 1988), personality (Rohde et al. 1990; Duggan et al. 1991; Shea et al. 1996; De Fruyt et al. 2006; Ormel et al. 2004b), psychosocial disability (Rohde et al. 1990; Ormel et al. 2004a), social skills (Zeiss \& Lewinsohn, 1988) as well as rumination, self-esteem and negative emotionality (Beevers et al. 2007). However, in all these studies virtually no evidence was found for the scar hypothesis. Any changes in the aforementioned variables were either concomitants of current (residual) depressive symptoms or scores were already elevated before the onset of the episode of MDD, thus probably representing pre-morbid risk factors rather than scars. The field is thus left with a situation in which 
(a)

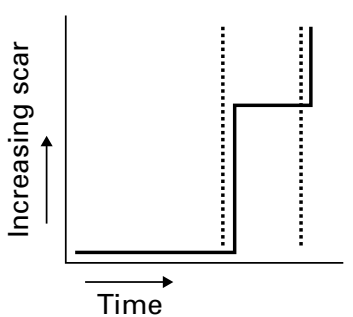

(b)

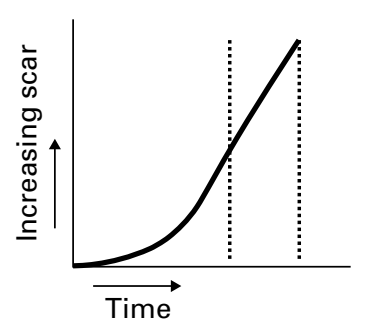

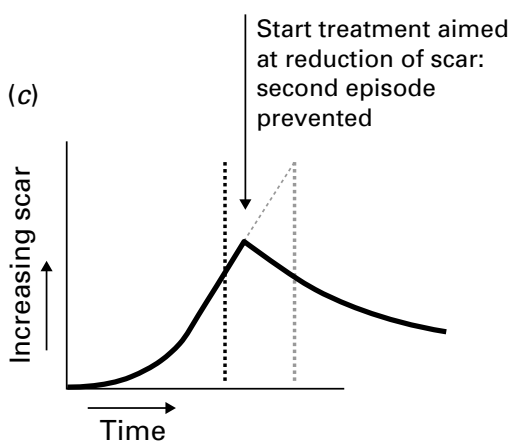

Fig. 1. The dichotomous scar model $(a)$ and the continuous scar model $(b, c)$. The figures are valid in a context where the individual experiences stress or subclinical depressive symptomatology. The $x$-axis represents time and the $y$-axis the increasing scar (一). The dotted lines represent episodes of depression (….). In panel (a), the scar develops suddenly following an episode of depression. In panel $(b)$, the scar develops gradually over time regardless of the arbitrary boundaries of fulfilling criteria for depression. Panel (c) depicts the hypothesis that scars are reversible and that (new) treatments aimed at reducing scars may prevent the development of further episodes of depression due to their effect on scar development.

vulnerability for onset of episodes of MDD seems to increase as a function of the number of episodes, suggestive of scarring, yet studies that try to examine the mechanisms involved fail to shed any light on the issue.

We will argue that methodological and conceptual complexities may underlie this discrepancy and propose a new approach to the concept of 'scars' for future research.

\section{Where and how should we look for the scar?}

\section{Dimensional approach}

Although the categorical approach of MDD in the Diagnostic and Statistical Manual of Mental Disorders (DSM)-IV may be useful in clinical settings, depression is probably best conceptualized as a dimensional construct rather than as a discrete diagnostic entity (Kendler et al. 1998; Hankin et al. 2005; Slade, 2007), although some controversy exists in the literature (Coyne, 1994; Flett et al. 1997; Beach \& Amir, 2003; Solomon et al. 2006). Strong arguments for the dimensional view of depression include the fairly consistent finding that subthreshold depression strongly increases risk for future MDD (Cuijpers \& Smit, 2004) and that subthreshold depression impacts considerably on functioning (Judd et al. 2002). The influence of underlying aetiological factors is therefore unlikely to be limited to man-made DSM-IV boundaries. Likewise, it is improbable that scars would only develop after an episode that fulfils the DSM-IV criteria. A more plausible hypothesis is that scars, if any, would develop proportionally to the amount of depressive symptoms experienced. This would mean that scars already develop gradually as a result of subtle subclinical depressive symptoms before the onset of a full-blown episode of MDD. This gradually increasing scar, as the catalyser of a vicious circle, may thus additionally constitute a risk factor for the first episode of MDD (see Fig. 1). Likewise, 'scarring' residual symptoms after MDD may additionally constitute a risk factor for relapse. This principle can be compared with the proposed vicious circle of the global warming of the earth. The warming of the atmosphere makes the ice on the North Pole melt. This allows the sun to shine upon the surface of the sea that was previously covered with ice, enabling it to warm up the sea even further and cause melting of additional ice. In this example, the melting of the ice would be the gradually developing 'scar' that subsequently by itself further increases the speed of warming up, eventually causing a point of global warming where humans experience the consequences. Likewise, in the case of MDD, negative emotionality and low self-esteem can be perceived as potential risk catalysers : they may be caused by negative environmental events, and at the same time induce risk for future negative (interpretations of) situations that, in turn, will build up even more scars. Similarly, exposure to stress (Hammen, 1991) itself could be a potential risk catalyser: depressive symptoms may foster life circumstances that increase the likelihood of exposure to stress that in turn further increase the individual's vulnerability to depression. If the proposition regarding the 'gradually increasing scar' is true then it is impossible to identify these scars using the dichotomous approach as described in the Introduction, since pre-morbid alterations will be identified as risk factors rather than scars resulting from subclinical depressive symptoms.

Thus, we propose that the scars that researchers wish to identify may develop gradually along the life cycle, proportionally to the severity and duration of the depressive symptoms experienced. 


\section{Sensitive to person-context interactions}

Cross-sectional, non-dynamic methodology in depression research will probably obscure the effects of scarring. Without taking into account the dynamic interplay between the person and his/her context, measures may not be sensitive enough to make a scar effect visible. For example, Segal et al. (2006) found that a greater cognitive reactivity of remitted depressed patients following induction of depressed mood increased the risk for relapse. Thus, the (re) activation of depressive thinking styles triggered by temporary dysphoric states may indicate vulnerability. In this study, dysfunctional cognitive attitudes would probably have remained inactive in the absence of an experimental mood induction paradigm, so that differences between controls and remitted patients would not have been detected. Thus, it is possible that scars are not immediately accessible and measurable with questionnaires, but that they can only be made visible using challenging experimental designs that activate a participant's vulnerability. Tools that are able to reveal subtle dysfunctions following experimental induction are available in the psychiatric literature. However, up to now they are not commonly used to evaluate possible scar effects. Examples of experimental tools in the biological domain are challenges of serotonergic pathways in the brain and the hypothalamic-pituitary-adrenal (HPA) axis. The former is achieved by acute tryptophan depletion (ATD) through lowering levels of tryptophan (essential for 5-hydroxytryptamine synthesis) that cannot be synthesized by the body. Bhagwagar \& Cowen (2008) recently suggested that ATD reveals latent dysfunctions in brain circuits that are associated with regulation of emotion in MDD-vulnerable subjects. Another biological experimental tool that may possibly reveal scars is the dexamethasone corticotropin-releasing hormone suppression (DEX/CRH) test. No HPAaxis abnormalities (e.g. alterations in basal cortisol secretion) are reported in recovered patients unless challenged by, for example, the DEX/CRH test (Zobel et al. 2001). To our knowledge, no studies have used these methodologies to investigate the process of scarring.

Another type of design that incorporates the dynamic interplay between an individual and his/her environment is the Experience Sampling Method (ESM) (Csikszentmihalyi \& Larson, 1987; Delespaul, 1995). In ESM research, individuals are asked to fill in a diary in response to a beep signal at random unpredictable moments of the day. The diary provides information on their current mood state, physical state, current activities, appraisal of the current social situation and recent (past hour) events, etc. This method enables investigators to assess subtle changes in dynamic real-life person-context interactions instead of traits measured in an experimental laboratory setting which typically isolates subjects from their daily life context. For example, the negative affective response to minor daily life stressors - daily life stresssensitivity-has been revealed as an important risk factor for the development of future depressive symptomatology (M. Wichers et al. unpublished observations). The nature of ESM measurements may benefit research aimed at identifying scars. Thus, in the search for scars, future research should use methods able to detect changes in subtle and contextdependent subject characteristics.

\section{Two processes: scarring due to depressive symptoms and due to the causes of depressive symptoms}

Another question that needs to be resolved is whether the hypothesized scarring is caused by the depressive symptomatology itself or by the triggers that caused the depressive symptoms in the first place, such as stress exposure, or by a combination of these factors. To date, studies that have investigated the existence of scar effects did not differentiate between the possible scarring effects of the depressive symptoms or preexisting conditions - such as extreme stress-before the onset of the depressive episode. Both the experience of stress and experience of depressive symptoms may produce scar effects. Post (1992) refers to two types of sensitization mechanisms: one related to the stressor and one to the experience of an affective episode. Psychosocial stress may induce a cascade of neurobiological events that have long-lasting consequences such as altered gene expression (Post, 1992). In this way, the individual may end up more vulnerable and exhibit altered behavioural responses to stress because of the sensitization by previous stressors (Post, 1992).

Alternatively or perhaps additionally, the experience of an affective episode may leave behind traces that predispose to further episodes as argued by Post (1992). A related view, developed from the above sensitization theory, that better fits with the continuous phenotype of depression and at the same time constitutes an integration between a cognitive and neurobiological perspective on depression, was proposed by Segal et al. (1996), based on the associative network theory. According to this theory, a network of inter-related nodes exists in which activation may spread from node to node. Concepts may bring to consciousness other closely related concepts via the spreading activation within this network. The likelihood of cognitive patterns being activated is dependent on the frequency of past usage analogous to 
biological mechanisms of neuronal learning. Based on this theory, it is argued that people strengthen their negative thought patterns every time they use them. The experience of severe adverse experiences may create a network of intensely negative 'depressogenic' themes that is related to the affect experienced. Thus, each time an individual experiences low mood (s)he is prone to activate other elements within the negative concepts network which will again strengthen-or sensitize - the paths of this network, making it more accessible each time a moment of low mood presents itself in the future (Segal et al. 1996). This view is compatible with the assumption that depressive symptoms over the whole continuum of depression may contribute to scar effects. A recent study showed that developmental stress exposures increased later daily life stress-sensitivity (conceptualized as negative affective response to minor daily stressors) (Wichers et al. 2009) which fits within the sensitization theory and the cognitive view on sensitization in depression. For example, early adversity may induce negative cognitive schemes (a scar due to a stressor) that become more readily activated each time they are used, i.e. at the time of experiencing stressors or mild dysphoric states (continuously increasing scar due to negative affective states). As a result, small daily life stressors may activate negative cognitive schemes with progressively lower thresholds, so that the subject responds with progressively stronger negative affect to daily life stressors.

As mentioned before, the higher the daily life stresssensitivity, the stronger its association with future increase in depressive symptoms and episodes of depression (Segal et al. 1996; Wichers et al. 2009; $\mathrm{M}$. Wichers et al. unpublished observations). A plausible biological substrate for the effect of early adversity on the development of a negative scheme is amygdala reactivity. Heightening of amygdala reactivity is known to follow traumatic experiences (Ganzel et al. 2007, 2008) and this increase is associated with automatic negative evaluation response tendencies and a negative bias in the interpretation of faces (Dannlowski et al. 2007a,b; Beck, 2008).

In conclusion, both stressors and negative mood states may be able to produce scars that are relevant to the vulnerability for depression. Additionally, these processes may work together in producing vulnerability and are probably gradually inducing an increased amount of scar over periods of time. However, no previous studies examining the existence of scars have tried to disentangle the two processes. Another issue is whether a threshold may exist after which scarring consolidates. Some evidence exists that, for example, the process of kindling (evident from the progressively reduced association between major life events and risk of each further depressive episode) involved in the risk for new depressive episodes reaches consolidation at a certain point after which the amount of acquired vulnerability stabilizes (Kendler et al. 2000). Future studies examining scar effects should try to take into account these processes in order to unravel the complex mechanisms of the progressively increasing vulnerability for depression due to scar effects.

\section{The issue of reversibility - can we heal the scar?}

Finally, the question arises whether a scar is reversible or not. The name 'scar' implies a permanent increase in vulnerability. However, biological plausibility may be higher for a 'scar' or vulnerability concept that has dynamic properties, something that can increase and decrease under certain circumstances. In recent years, the concept of epigenetics, evidence that genetic function is not static but plastic, has also gained attention within the field of psychopathology research. The idea that epigenetic effects also apply to psychopathology may help in identifying evidence for the biological plausibility of reversibility of scars. Gene function can be altered following adverse circumstances and may become expressed as a change in behaviour (scarring effect). Recent studies have reported associations between epigenetic status and mood or depression (Oberlander et al. 2008; Philibert et al. 2008; Poulter et al. 2008). Although speculative, it may be parsimonious to hypothesize that certain environmental influences may also change genetic epi-mutations back into their default states. This may subsequently reduce the amount of scarring, the risk for mood abnormalities, and formation of psychopathology. However, to date this has not been studied.

There is biological plausibility for reversibility, not only at the level of genetics but also at the level of neuronal mechanisms of learning. For instance, in the example described earlier, based on the associative network theory, one would predict that not using the connections between negative concepts will weaken the strength of the associations, increase the threshold for activation and thus decrease this type of vulnerability. Not using specific (negative) network associations may be a very active process which can reduce previously developed scars.

In addition, evidence from a recent study (Wichers et al. 2007b) is suggestive of scar reversibility. The dynamic person-context interaction concept of daily life stress-sensitivity can be seen as scar of past stressors and dysphoric states according to the new definition proposed in this paper. It gradually increases following early stress exposures (Wichers et al. 2009), is associated with depressive symptoms (Wichers et al. 
$2007 a$ ) and predicts the development of future new affective symptoms and episodes of MDD (M. Wichers et al. unpublished observations). For this potential scar, evidence exists that other factors may decrease its effects. It has been found that the experience of positive emotions during stressors decreases the level of stress-sensitivity (Wichers et al. 2007b). Moreover, positive emotions neutralize the expression of genetic risk associated with increased daily life stress-sensitivity (Wichers et al. 2008). Thus, there are mechanisms that may decrease the impact of potential scars.

A dynamic view on scars encourages a more optimistic and less deterministic view on vulnerability. In addition, it emphasizes the role of resilience in depressive disorder: mechanisms implicated in positive traits and strategies of the subject that are relatively independent from vulnerability mechanisms may have crucial importance for diminishing scars and preventing (recurrence of) depressive symptomatology.

\section{Scars and treatment of depression}

Knowledge of reversibility of scars is highly relevant to the treatment of MDD. As the scars of previous experienced stress or negative affective states form a vicious circle by which people become more and more depressed (and thus develop new scars), treatments for MDD should also be focused on the reduction of scarring effects. Only by disruption of this vicious cycle can the long-term course of MDD be bent into a more favourable direction. This makes the discovery of the basic mechanisms involved in scarring a priority in depression research.

Some treatments already may work by impacting on the processes of scarring. A new treatment, ' mindfulness-based cognitive therapy' (Teasdale et al. 2000, 2002), attempts to teach individuals to focus attention on the present moment and to let go of negative thoughts about past experiences or future worries. Subjects with sensitized negative cognitive schemes may profit from this approach as it helps them to detach from thoughts that activate these schemes. By actively avoiding the spreading of activation through the negative cognitive schemes, the strength of these paths will eventually diminish. Thus, people will desensitize their network of negative cognitions, and thus their scar, that caused negative emotions to flourish (Sheppard \& Teasdale, 2004). Cognitive behavioural therapy (CBT) may also be effective partly through the desensitization of the network of negative cognitions. Segal et al. (1999) showed that after negative mood induction, patients successfully treated with CBT exhibited significantly less dysfunctional cognitions than those successfully treated with pharmacotherapy. Thus, CBT may be able to undo relevant underlying cognitive scars which were not affected by medication treatment.

Another future application of scar research to clinical practice is the assessment of change of potential scars during standard therapy. Dynamic personcontext phenotypes (hereafter: ESM phenotypes) such as 'stress-sensitivity' are, as argued above, potential scars and can be measured using ESM technology. The assessment of treatment response in terms of scar changes may induce new possibilities. Instead of assessing treatment response in terms of remission and recovery, for which monitoring of change in depressive symptoms is sufficient, the additional assessment of 'scar change' may be useful as an indicator of risk for future depressive symptomatology. A recent study showed that in remitted depressed subjects, ESM phenotypes, independently from baseline depressive symptoms, contribute to the prediction of future symptoms and relapse (M. Wichers et al. unpublished observations). Assessment of a reduction in the mechanisms underlying the continuation of symptoms the scars - during treatment may constitute a complementary way to assess treatment response (in addition to assessment of decrease in symptoms only) and may increase power to predict future course of depression.

\section{Concluding remarks}

The progressively growing risk of depression relapse with a higher number of past experienced episodes of depression provides strong support for the theory that scars related to past experiences may increase a person's level of vulnerability. However, studies have generally not been successful in detecting scars and their mechanisms. We propose a new approach to examine the concept of a 'scar' that (i) is based on a dimensional view on depression, i.e. that scars may develop following depressive symptoms at all points of the continuum from low to high depression, (ii) uses methods that take into account the dynamic interplay between the person and his context to be able to detect subtle changes in person-environment interplay, (iii) differentiates between scars following depression and scars following that what caused the depression such as stress exposure, and (iv) holds a dynamic view of the concept of 'scar' in that it hypothesizes that scars can wax and wane, stimulating research into mechanisms of resilience.

If scars are conceived as continuously and gradually developing from interactions between the effects of lingering traces of stress and the experience of low mood, it is implied that scars operate at a subclinical as well as a clinical level. Furthermore, starting from the subclinical level, scars may keep growing-making 
people more and more vulnerable - and create a vicious circle. The above view necessitates a new approach in the examination of scars that may stimulate the finding of new entries in the puzzle of the development of vulnerability and resilience. Moreover, this approach may provide insights that help to develop new therapies for MDD aimed at decreasing scar(s) and complementary assessment methods for evaluation of treatment response.

\section{Acknowledgements}

M.C.W. was supported by the Dutch Medical Council (VENI grant no. 916.76.147).

\section{Declaration of Interest}

None.

\section{References}

Barnett PA, Gotlib IH (1988). Psychosocial functioning and depression: distinguishing among antecedents, concomitants, and consequences. Psychological Bulletin 104, 97-126.

Beach SR, Amir N (2003). Is depression taxonic, dimensional, or both? Journal of Abnormal Psychology 112, 228-236.

Beck AT (2008). The evolution of the cognitive model of depression and its neurobiological correlates. American Journal of Psychiatry 165, 969-977.

Beevers CG, Rohde P, Stice E, Nolen-Hoeksema S (2007). Recovery from major depressive disorder among female adolescents: a prospective test of the scar hypothesis. Journal of Consulting and Clinical Psychology 75, 888-900.

Bhagwagar Z, Cowen PJ (2008). 'It's not over when it's over': persistent neurobiological abnormalities in recovered depressed patients. Psychological Medicine 38, 307-313.

Burcusa SL, Iacono WG (2007). Risk for recurrence in depression. Clinical Psychology Review 27, 959-985.

Coyne JC (1994). Self-reported distress : analog or Ersatz depression? Psychological Bulletin 116, 29-45.

Csikszentmihalyi M, Larson R (1987). Validity and reliability of the Experience-Sampling Method. Journal of Nervous and Mental Disease 175, 526-536.

Cuijpers P, Smit F (2004). Subthreshold depression as a risk indicator for major depressive disorder: a systematic review of prospective studies. Acta Psychiatrica Scandinavica 109, 325-331.

Dannlowski U, Ohrmann P, Bauer J, Kugel H, Arolt V, Heindel W, Kersting A, Baune BT, Suslow T (2007a). Amygdala reactivity to masked negative faces is associated with automatic judgmental bias in major depression: a $3 \mathrm{~T}$ fMRI study. Journal of Psychiatry and Neuroscience 32, 423-429.

Dannlowski U, Ohrmann P, Bauer J, Kugel H, Arolt V, Heindel W, Suslow T (2007b). Amygdala reactivity predicts automatic negative evaluations for facial emotions. Psychiatry Research 154, 13-20.

De Fruyt F, Van Leeuwen K, Bagby RM, Rolland JP, Rouillon F (2006). Assessing and interpreting personality change and continuity in patients treated for major depression. Psychological Assessment 18, 71-80.

Delespaul P (1995). Assessing Schizophrenia in Daily Life: The Experience Sampling Method. University of Limburg: Maastricht.

Duggan CF, Sham P, Lee AS, Murray RM (1991). Does recurrent depression lead to a change in neuroticism? Psychological Medicine 21, 985-990.

Flett GL, Vredenburg K, Krames L (1997). The continuity of depression in clinical and nonclinical samples. Psychological Bulletin 121, 395-416.

Ganzel B, Casey BJ, Glover G, Voss HU, Temple E (2007). The aftermath of 9/11: effect of intensity and recency of trauma on outcome. Emotion 7, 227-238.

Ganzel BL, Kim P, Glover GH, Temple E (2008). Resilience after 9/11: multimodal neuroimaging evidence for stressrelated change in the healthy adult brain. Neuroimage 40, 788-795.

Hammen C (1991). Generation of stress in the course of unipolar depression. Journal of Abnormal Psychology 100, 555-561.

Hankin BL, Fraley RC, Lahey BB, Waldman ID (2005). Is depression best viewed as a continuum or discrete category? A taxometric analysis of childhood and adolescent depression in a population-based sample. Journal of Abnormal Psychology 114, 96-110.

Judd LL, Schettler PJ, Akiskal HS (2002). The prevalence, clinical relevance, and public health significance of subthreshold depressions. Psychiatric Clinics of North America 25, 685-698.

Kendler KS, Gardner Jr. CO (1998). Boundaries of major depression: an evaluation of DSM-IV criteria. American Journal of Psychiatry 155, 172-177.

Kendler KS, Thornton LM, Gardner CO (2000). Stressful life events and previous episodes in the etiology of major depression in women: an evaluation of the 'kindling' hypothesis. American Journal of Psychiatry 157, 1243-1251.

Lewinsohn PM, Steinmetz JL, Larson DW, Franklin J (1981). Depression-related cognitions: antecedent or consequence? Journal of Abnormal Psychology 90, 213-219.

Monroe SM, Harkness KL (2005). Life stress, the 'kindling' hypothesis, and the recurrence of depression: considerations from a life stress perspective. Psychological Review 112, 417-445.

Oberlander TF, Weinberg J, Papsdorf M, Grunau R, Misri S, Devlin AM (2008). Prenatal exposure to maternal depression, neonatal methylation of human glucocorticoid receptor gene (NR3C1) and infant cortisol stress responses. Epigenetics 3, 97-106.

Ormel J, Oldehinkel AJ, Nolen WA, Vollebergh W (2004a). Psychosocial disability before, during, and after a major depressive episode: a 3-wave population-based study of state, scar, and trait effects. Archives of General Psychiatry 61, 387-392.

Ormel J, Oldehinkel AJ, Vollebergh W (2004b)

Vulnerability before, during, and after a major depressive 
episode: a 3-wave population-based study. Archives of General Psychiatry 61, 990-996.

Pettit JW, Lewinsohn PM, Joiner Jr. TE (2006). Propagation of major depressive disorder: relationship between first episode symptoms and recurrence. Psychiatry Research 141, 271-278.

Philibert RA, Sandhu H, Hollenbeck N, Gunter T, Adams W, Madan A (2008). The relationship of 5HTT (SLC6A4) methylation and genotype on mRNA expression and liability to major depression and alcohol dependence in subjects from the Iowa Adoption Studies. American Journal of Medical Genetics Part B 147B, 543-549.

Post RM (1992). Transduction of psychosocial stress into the neurobiology of recurrent affective disorder. American Journal of Psychiatry 149, 999-1010.

Poulter MO, Du L, Weaver IC, Palkovits M, Faludi G, Merali Z, Szyf M, Anisman H (2008). GABA(A) receptor promoter hypermethylation in suicide brain: implications for the involvement of epigenetic processes. Biological Psychiatry 64, 645-652.

Rohde P, Lewinsohn PM, Seeley JR (1990). Are people changed by the experience of having an episode of depression? A further test of the scar hypothesis. Journal of Abnormal Psychology 99, 264-271.

Segal ZV, Gemar M, Williams S (1999). Differential cognitive response to a mood challenge following successful cognitive therapy or pharmacotherapy for unipolar depression. Journal of Abnormal Psychology 108, 3-10.

Segal ZV, Kennedy S, Gemar M, Hood K, Pedersen R, Buis T (2006). Cognitive reactivity to sad mood provocation and the prediction of depressive relapse. Archives of General Psychiatry 63, 749-755.

Segal ZV, Williams JM, Teasdale JD, Gemar M (1996). A cognitive science perspective on kindling and episode sensitization in recurrent affective disorder. Psychological Medicine 26, 371-380.

Shea MT, Leon AC, Mueller TI, Solomon DA, Warshaw MG, Keller MB (1996). Does major depression result in lasting personality change? American Journal of Psychiatry 153, 1404-1410.

Sheppard LC, Teasdale JD (2004). How does dysfunctional thinking decrease during recovery from major depression? Journal of Abnormal Psychology 113, 64-71.

Slade T (2007). Taxometric investigation of depression: evidence of consistent latent structure across clinical and community samples. Australian and New Zealand Journal of Psychiatry 41, 403-410.
Solomon A, Ruscio J, Seeley JR, Lewinsohn PM (2006). A taxometric investigation of unipolar depression in a large community sample. Psychological Medicine 36, 973-985.

Stroud CB, Davila J, Moyer A (2008). The relationship between stress and depression in first onsets versus recurrences: a meta-analytic review. Journal of Abnormal Psychology 117, 206-213.

Teasdale JD, Moore RG, Hayhurst H, Pope M, Williams S, Segal ZV (2002). Metacognitive awareness and prevention of relapse in depression: empirical evidence. Journal of Consulting and Clinical Psychology 70, 275-287.

Teasdale JD, Segal ZV, Williams JM, Ridgeway VA, Soulsby JM, Lau MA (2000). Prevention of relapse/ recurrence in major depression by mindfulness-based cognitive therapy. Journal of Consulting and Clinical Psychology 68, 615-623.

Wichers M, Kenis G, Jacobs N, Myin-Germeys I, Schruers K, Mengelers R, Delespaul P, Derom C, Vlietinck R, van Os J (2008). The psychology of psychiatric genetics: evidence that positive emotions in females moderate genetic sensitivity to social stress associated with the BDNF Val ${ }^{66}$ Met polymorphism. Journal of Abnormal Psychology 117, 699-704.

Wichers M, Myin-Germeys I, Jacobs N, Peeters F, Kenis G, Derom C, Vlietinck R, Delespaul P, Van Os J (2007a). Genetic risk of depression and stress-induced negative affect in daily life. British Journal of Psychiatry 191, 218-223.

Wichers M, Schrijvers D, Geschwind N, Jacobs N, Myin-Germeys I, Thiery E, Derom C, Sabbe B, Peeters F, Delespaul P, van Os J (2009). Mechanisms of gene-environment interactions in depression: evidence that genes potentiate multiple sources of adversity. Psychological Medicine 39, 1077-1086.

Wichers MC, Myin-Germeys I, Jacobs N, Peeters F, Kenis G, Derom C, Vlietinck R, Delespaul P, van Os J (2007b). Evidence that moment-to-moment variation in positive emotions buffer genetic risk for depression: a momentary assessment twin study. Acta Psychiatrica Scandinavica 115, 451-457.

Zeiss AM, Lewinsohn PM (1988). Enduring deficits after remissions of depression: a test of the scar hypothesis. Behaviour Research and Therapy 26, 151-158.

Zobel AW, Nickel T, Sonntag A, Uhr M, Holsboer F, Ising $\mathbf{M}$ (2001). Cortisol response in the combined dexamethasone/CRH test as predictor of relapse in patients with remitted depression. A prospective study. Journal of Psychiatric Research 35, 83-94. 